\title{
Manual responses to visual stimuli:early and late facilitatory effects due to the offset of a peripheral cue
}

\author{
Respostas manuais a estím ulos visuais: ef eitos facilitatórios precoces etar dios \\ relacionados ao desaparecimen to deuma dica periférica
}

Walter Machado-Pinh eir $0^{1,2}$

Luiz G. Gaw ryszew ski²

Antônio Pereira J r. ${ }^{3}$

\footnotetext{
Departamento de Fisiologia e Farmacologia, Instituto Biomédico, Universidade Federal Fluminense; ${ }^{2}$ Departamento de Neurobiologia, Instituto de Biologia, Universidade Federal Fluminense; ${ }^{3}$ Laboratorio de Neuroanatomia Funcional, Departamento de Fisiologia, Universidade Federal do Pará. Correspondence concerning this article should be addressed to Luiz G. Gawryszewski, Departamento de Neurobiologia, Universidade Federal Fluminense, Caixa Postal 100.180, CEP 24001-970, Niterói, RJ, Brasil (email: gnelggw@vm.uff.br); phone 55-21-7171161 / Fax: 55-21-2719- 5934 / 55-21-2620-3100.
}

\begin{tabular}{l} 
A BST R A CT \\
\hline Manual and saccadic reaction times (MRTs and SRTs) are reduced when \\
a warning signal precedes the onset of a target. The decreasing on SRTs \\
observed after the offset of a fixation point has been called the gap effect. \\
Different theories have been proposed to explain it. According to some \\
authors, the offset also allows the saccadic system to generate a separate \\
population of SRTs, the express saccades. Nevertheless there is no \\
agreement about the influence of the offset of a peripheral stimulus on \\
MRT. In two experiments we tested the effects of a peripheral visual offset \\
used as preparatory signal on MRTs to a target after variable intervals. We \\
found a reduction on MRT at short (200-300ms) and long (1300-2000 ms) \\
intervals after the peripheral offset. MRT distribution shifted toward short \\
latencies, which sometimes formed a separate population. Since MRTs \\
obtained at long intervals were affected by the introduction of catch trials, \\
while MRTs at short intervals were not, we propose that two different \\
mechanisms are involved in the decreasing of MRTs: warning and tempo- \\
ral expectancy. Our data support the hypothesis that the temporal com- \\
ponent involved with the preparatory stages for motor responses can be \\
shared by saccadic movements and key press responses, allowing the \\
reduction on motor latencies after the visual offset in the gap paradigm. Our \\
data corroborate the three components model for the gap effect. In our \\
view, the question of the existence or not of a gap effect for manual \\
responses is essentially conceptual.
\end{tabular}

Keywords: Reaction time; Preparation; Expectancy; Gap effect; Visual offset; Express responses

\section{INTRODUCTION}

Since the last century there has been general agreement that reaction times are reduced when a warning signal precedes the onset of a target (for details $\left.{ }^{(1)}\right)$. Ross and Ross ${ }^{(2-3)}$ showed that manual reaction times (MRTs) to a visual target were equally reduced no matter if the preparatory signal (S1) was the onset or the offset of a foveal stimulus. In contrast, the reduction on saccadic reaction times (SRTs) was greater when the offset was used instead of the onset of a visual preparatory stimulus ${ }^{(3)}$. However, data obtained by our group ${ }^{(4-5)}$ have shown that MRTs are also differentially affected by the previous onset or offset of a visual stimulus. In one of these papers $^{(5)}$ onset and offset of a peripheral S1 were used as a warning signal. Our results showed that $\mathrm{S} 1$ offset produced MRTs shorter than those observed when the onset of S1 preceded the target (S2). This facilitation on 
MRTs for offset trials was observed for S2 presented both contra- and ipsolaterally to S1. In short, our data support the idea that the onset or offset of a visual non-informative cue produce different effects on MRT to a second stimulus.

The interest in the different effects of S1 onset or offset on motor responses to S2 has increased with the studies about phenomena such as the gap effect and the express saccades. Saslow $^{(6)}$ was the first to show that if the fixation point (FP) disappeared prior to target onset (gap paradigm) SRTs were reduced. When the FP remained on throughout the trial (overlap paradigm), the mean SRT was about $250 \mathrm{~ms}$; when the FP offset was simultaneous to the stimulus onset (gap 0), the mean SRT was about $200 \mathrm{~ms}$; and when the FP disappeared $200 \mathrm{~ms}$ before the target onset (gap paradigm), SRTs decreased to about $150 \mathrm{~ms}$. This reduction on SRTs has been called "the gap effect" (for details ${ }^{(7)}$ ).

Fischer and Boch ${ }^{(8)}$ in monkeys and Fischer and Ramsperger ${ }^{(9)}$ in humans confirmed Saslow's findings regarding the gap paradigm and showed additionally that SRT distribution in many subjects can form two distinct modes or peaks. In humans, the first peak occurred around 100-120 ms and the second one occurred around 160-180 ms. The very short latency group in the SRT distribution was called Express Saccades $\mathrm{ESs}^{(7)}$. According to Fischer, "express saccades are defined by their extremely short reaction times ( $70 \mathrm{~ms}$ in monkey, $100 \mathrm{~ms}$ in man), which often form a separate peak in the reaction time distribution" $^{(7)}$ (p. 553) - bimodal distribution criterion. Moreover, after training, some subjects were able to reduce or even eliminate the later peaks, thus resulting in an unimodal distribution with a single peak around $100 \mathrm{~ms}^{(7)}$ - absolute latency criterion. Other researchers ${ }^{(10-14)}$, however, though confirming the reduction on SRTs with the gap paradigm, do not support the idea of ESs. According to their interpretation, neither the bimodality nor the latency criterion are convincing enough to propose the existence of ESs.

Some important additional findings were reported by Mayfrank et al. ${ }^{(15)}$ and Braun and Breitmeyer ${ }^{(16)}$. In these studies, the onset of the target was preceded by the offset of a peripheral visual cue, while FP remained unchanged, i.e. remained on. Both studies showed that SRTs were reduced and the ESs demonstrated after a peripheral offset, even with no FP offset. In agreement with Saslow ${ }^{(6)}$, they also showed that the best interval to produce the reduction on SRTs was between 200 and $300 \mathrm{~ms}$.

The mechanisms underlying the reduction of SRTs in the gap paradigm are not yet completely understood (for a review $\left.{ }^{(7)}\right)$. It is also not clear whether the reduction on reaction times observed with visual offset represents a general sensory-motor phenomenon or if they are restricted to the saccadic system. In fact, some authors ${ }^{(17-20)}$ have tried to elicit express manual responses using choice reaction time paradigms. In short, no evidence has been presented for the existence of a sub-population of manual reaction times corresponding to the express responses. These results led us to study the effects of visual offsets on manual responses by changing some of the experimental procedures used by other researchers. In the present study, we employed the simple reaction time paradigm, which, in our view, is best suited to demonstrate "reflexlike" manual responses. We also decided to use a peripheral offset instead of a FP offset (as Mayfrank et al. ${ }^{(15)}$ and Braun and Breitmeyer ${ }^{(16)}$ did) and, to avoid anticipatory errors and/or time-locked manual responses, we used variable intervals between the offset of S1 and the onset of S2. Thus, our experiments differ from most of the previous ones in three important ways: the use of a simple manual reaction times paradigm; the use of a peripheral stimulus offset instead of a fixation point offset; and the use of a variable array of intervals, since most of the studies used a constant interval or a blocked array of intervals (i.e., during a block of trials, the interval was constant - typically $200 \mathrm{~ms}$ ).

\section{EXPERIMENT 1}

In the first experiment, we collected manual reaction times to visual targets after a peripheral visual offset in order to determine whether the findings observed by Mayfrank et al. ${ }^{(15)}$ and Braun and Breitmeyer ${ }^{(16)}$ concerning SRTs also apply to MRTs. Our main questions are: 1) Is there a reduction on simple MRT when a peripheral stimulus offset precedes the target onset, such as occurred for SRT? 2) If it occurs, what is the time course? 3) Is it possible to distinguish different populations of MRTs in the latency distribution, just as it has been found for SRTs?

MATERIAL AND METHODS

\section{Subjects}

Eight subjects (four males and four females) participated voluntarily in this study. All of them were right-handed according to the Edinburgh Inventory ${ }^{(21)}$, had normal or corrected vision, and their ages ranged from 20 to 35 years. They were undergraduate or graduated students at Federal Fluminense University, and had already participated in previous experiments in our laboratory, although they were naive with respect to the goals of the present experiment.

\section{Apparatus}

The experiments took place in a sound-attenuated room, under dim ambient light. The subjects sat in front of a CRT screen driven by a PC-486 microcomputer, which timed the stimuli and recorded the MRT. The head was positioned in a head-and-chin rest so that the distance between the eyes and the screen was approximately $57 \mathrm{~cm}$. Before data collection, subjects were given some training and the importance of maintaining fixation was stressed. During this training, eye movements were monitored by the experimenter sitting behind the subject, using a suitably oriented mirror. The observer did not notice any shift in gaze directions before target presentation. 
Moreover, in this experiment, the target was always presented around the fixation point (see below), i.e., in a foveal region.

\section{Procedure}

Each trial began with the simultaneous presentation of a central point (fixation point - FP) and a square $\left(\mathrm{S} 1-0.5^{\circ} \times 0.5^{\circ}\right)$ located $4^{\circ}$ above it. After $700 \mathrm{~ms}, \mathrm{~S} 1$ went off and after a variable interval, the imperative stimulus (S2 - an identical square) flashed for $100 \mathrm{~ms}$ around the FP. The position of S2 close to the FP helped preventing eye movements. The intervals between $\mathrm{S} 1$ offset and the S2 onset were 0, 100, 200, 300, 500 and $2000 \mathrm{~ms}$ (Figure 1). These intervals had the same probability of occurrence and varied at random. The subjects were instructed to fixate at the FP and to use the offset of S1 as a cue for the onset of S2. They were also instructed to press a microswitch with the right index finger as soon as they detected S2. After each manual response, its latency (MRT) appeared, in milliseconds, on the screen for 1000 ms. Next trial began immediately after this presentation. Stimulus luminance was $11.5 \mathrm{~cd} / \mathrm{m}^{2}$ and background luminance was $0.2 \mathrm{~cd} / \mathrm{m}^{2}$. All the subjects performed three sessions of 300 trials in separate days (approximately 30 minutes per session). The sessions consisted in four blocks of 75 trials interspersed with one or two minutes to rest. Fifty MRT for each interval were measured daily. The first session was considered to be training, and its results were not considered in analysis. MRTs shorter than $100 \mathrm{~ms}$ or longer than $700 \mathrm{~ms}$ were considered to be errors and generated a written message "anticipation" or "slow response", respectively, which remained on the screen for $1000 \mathrm{~ms}$. These trials were repeated at the end of each session.

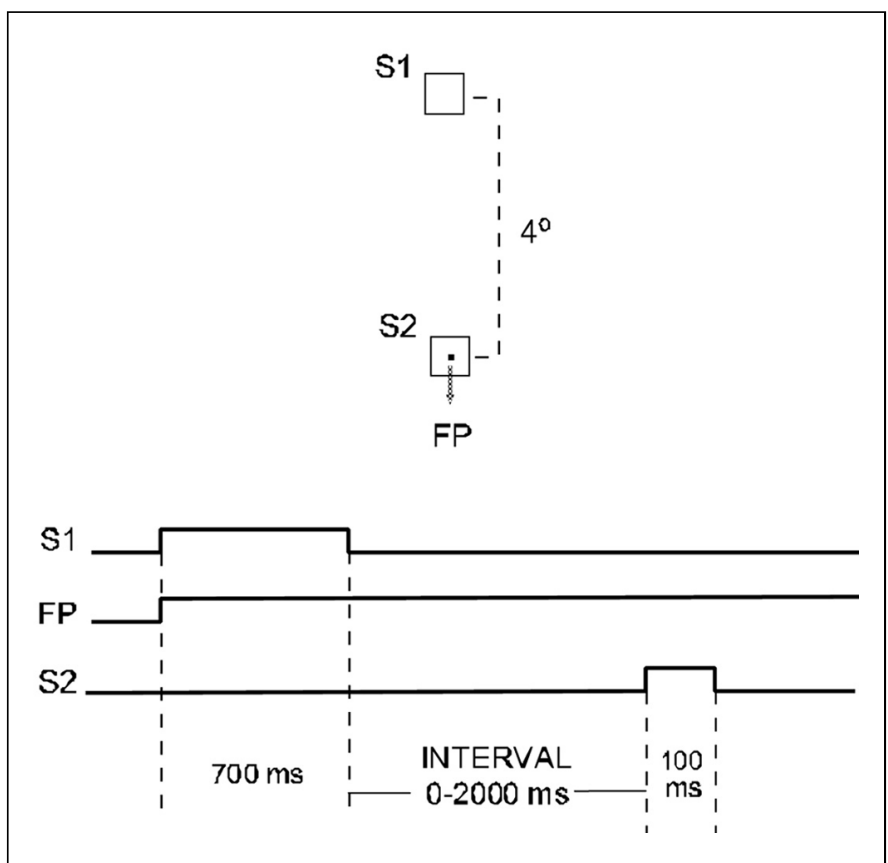

Figure 1 - Schematic representation of stimulus display; and temporal sequence of occurrence of the fixation point (FP), the first - preparatory - stimulus (S1) and the imperative stimulus (S2) for the first experiment
The medians of MRTs obtained in the second and third days were submitted to an analysis of variance (ANOVA) in which "day" (second and third) and "interval" (0, 100, 200, 300,500 and $2000 \mathrm{~ms}$ ) were used as within-subjects factors. We also performed a post-hoc analysis using Newman-Keuls method. The significance level adopted was $p<0.05$.

\section{RESULTSAND DISCUSSION}

In this first experiment, the error-trials corresponded to $4.33 \%$ (208 errors in 4800 trials), and almost all of them were anticipations (MRTs shorter than $100 \mathrm{~ms}$ ). These errors tended to be equally distributed among subjects and between second and third days. However, anticipations increased for the longest intervals: from 19 errors at the interval $200 \mathrm{~ms}$ to 88 errors at the interval of $2000 \mathrm{~ms}$.

The ANOVA showed a significant effect of "interval" $(F(5.35)=26.871, p<0.001)$ but not "day" $(F(1,7)=0.123, p=$ $0.733)$ on the MRTs. No interaction was observed between the two factors $(F(5.35)=0.256, p=0.932)$. Figure 2 shows the variation of MRTs as a function of stimulus interval. The posthoc analysis showed that manual responses were longer for the interval of $0 \mathrm{~ms}(248 \mathrm{~ms})$ than for any other interval. MRTs for the intervals of 200, 300 and $2000 \mathrm{~ms}$ did not differ among them $(213,217$ and $216 \mathrm{~ms}$, respectively) and were shorter than the others. MRTs for the intervals of 100 and $500 \mathrm{~ms}$ did not differ (226 and $228 \mathrm{~ms}$, respectively), but were statistically different from the others. Thus, two zones of facilitation for manual responses were found: one at 200-300 ms and another at the longest interval (2000 ms).

The time course of the first facilitation is quite similar to that observed in the gap paradigm for saccades (for a review ${ }^{(7)}$ ). Indeed, in order to define the best interval to reduce SRTs,

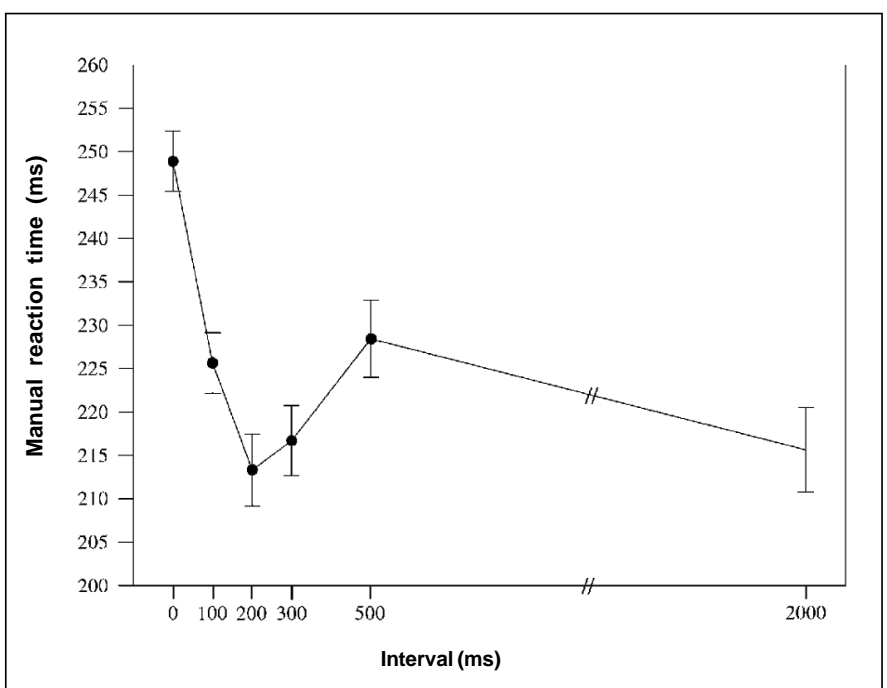

Figure 2 - Mean latency of manual reaction times (ordinate) as a function of the interval (abscissa) for the eight subjects. The error bars indicate \pm 1 standard error of the mean 
Mayfrank et al. ${ }^{(15)}$ and Braun and Breitmeyer ${ }^{(16)}$ tested the effects of different gap duration (intervals) on SRT. Both studies concluded that the optimal interval was 200-300 ms, and SRTs were not so fast for shorter $(50 \mathrm{~ms})$ or longer $(500 \mathrm{~ms})$ intervals. The intervals of 200-300 ms were also the most effective in generating a noticeable peak of express saccades. On both studies with SRTs, the interval was blocked, i.e., during a block of trials the interval was constant. In our experiment, the intervals were always randomly distributed during the test. Despite this fact, we observed that the intervals of 200-300 ms were also very efficient in reducing MRTs.

MRT distributions were made for the eight subjects with the data of the second and third days grouped. Therefore, there were 100 MRTs for each tested interval in the distributions. It was used a bin width of $10 \mathrm{~ms}$, i.e., the first bin included MRTs from 120 to $129 \mathrm{~ms}$, and the last from 310 to $319 \mathrm{~ms}$. Figure 3 shows data from one subject for the six tested intervals. From 0 to $300 \mathrm{~ms}$ intervals the distributions are shifted toward shorter MRTs, while longer reaction times are more frequent at interval 500. Finally, there is a tendency toward shorter MRTs at interval 2000. Figure 4 shows the MRT distributions for the eight subjects for the intervals of 0 ,

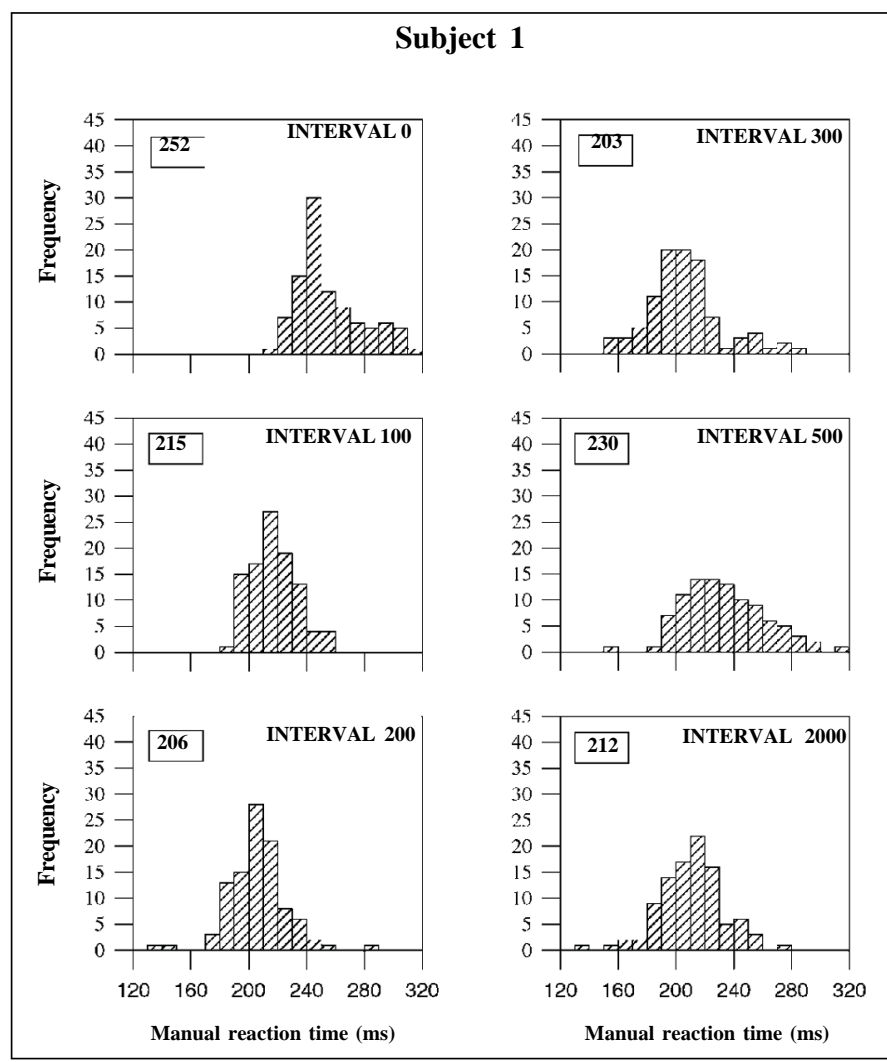

Figure 3 - Distribution of manual reaction times in the six tested intervals for a subject (subject 1). The number of manual responses - frequency (ordinate) was plotted as a function of manual reaction times (abscissa). It was used a bin width of $\mathbf{1 0} \mathbf{~ m s}$ and there were $\mathbf{1 0 0}$ manual responses per condition. The number in the box on the upperleft of each graph represents the median of the manual reaction times (in $\mathrm{ms}$ ) for that interval
200 or 300 and $2000 \mathrm{~ms}$. All subjects showed shorter MRTs at intervals $200 / 300$ and $2000 \mathrm{~ms}$ in relation to the $0 \mathrm{~ms}$ interval. Notice that distinct profiles of MRT distributions emerged for the eight subjects. For some subjects a population of MRTs can be seen at short latencies: subject \#2 showed a unimodal distribution peaking at about $170-180 \mathrm{~ms}$ for intervals 300 and 2000. For subject \#6 a peak occurred at $180-190 \mathrm{~ms}$ for interval 2000. Unimodal distributions were also present for subjects \#1 and \#8 (peaks at about the latencies of 200 and $210 \mathrm{~ms}$ ) at intervals 200 and 2000, and for subjects \#4 and \#7 at interval 2000 (peaks at about $220 \mathrm{~ms}$ ). MRT distribution for subjects \#3 and \#5 revealed almost no MRT shorter than $200 \mathrm{~ms}$. In fact, for these subjects, the first peak of MRTs on their distribution was around the latency of $220 \mathrm{~ms}$.
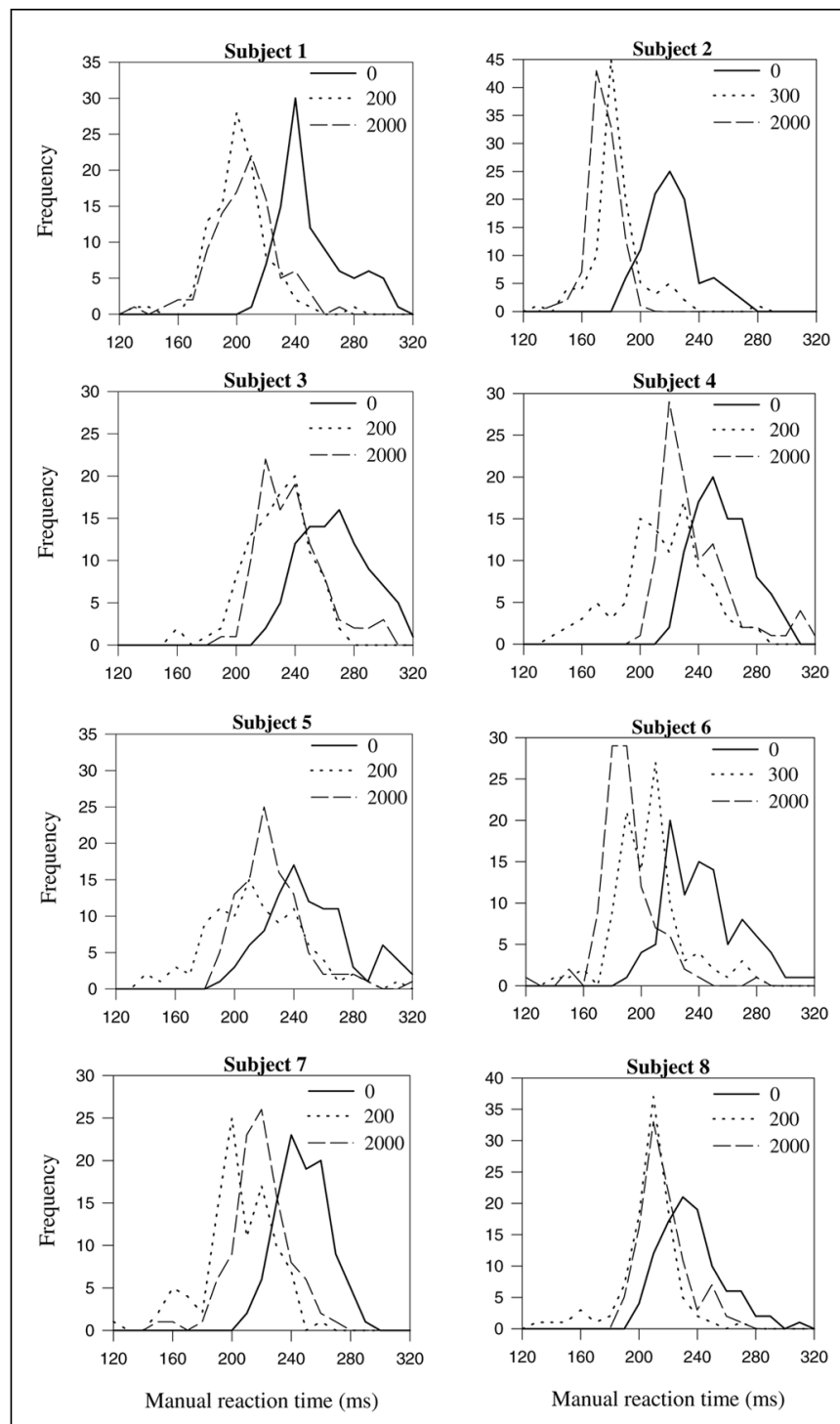

Figure 4 - Distribution of manual reaction times in the intervals of 0 200 or 300 and 2000 ms for the eight subjects. The number of manual responses - frequency (ordinate) was plotted as a function of manual reaction times (abscissa). It was used a bin width of $10 \mathrm{~ms}$ and there were 100 manual responses per condition 
Our data also showed that MRT distributions were more scattered than those observed for saccadic responses. Several profiles of distributions emerged and tended to be more variable across subjects in relation to the studies with $\mathrm{SRTs}^{(16)}$. However, despite this variability, two subjects (\#2 and \#6) had short MRTs forming a peak at about the latency of $180 \mathrm{~ms}$. For others (e.g., \#1, \#7 and \#8), a population of MRTs was found peaking at about $200-210 \mathrm{~ms}$. This population of short MRTs is completely absent at the interval of $0 \mathrm{~ms}$ for all subjects. In summary, leftward shifts on manual latencies were observed for short (200-300 ms) and long (2000 ms) intervals. The offset of a peripheral S1 is able to reduce and induce shifts toward short latencies on MRTs.

The second facilitatory zone, found at the interval of $2000 \mathrm{~ms}$, however, is unexpected given that this later facilitatory temporal zone was not observed for saccadic eye movements. In fact, Mayfrank et al. ${ }^{(15)}$ reported a decrease in the population of ESs at the longest tested intervals (in their case, $600 / 800 \mathrm{~ms}$ ). We believe that this later facilitation is due to a more general effect related to the expectancy, by the subject, that a stimulus which did not occur at short intervals will certainly appear later, at $2000 \mathrm{~ms}$. According to this point of view, expectancy (the preparatory mechanism that takes place when someone is waiting for a stimulus that will certainly occur) would have a major influence at the longest interval, but little or no effect at short intervals. This hypothesis was tested in a second experiment. Moreover, to be sure that the effect observed at long intervals was not due to the anticipation of the exact moment of target occurrence, we will vary the longest interval from 1300 to $1900 \mathrm{~ms}$.

\section{EXPERIMENT 2}

In this experiment we tested the sensibility of the two facilitatory zones observed in experiment 1 to the introduction of catch trials. As mentioned above, if expectancy has a major effect on MRTs at the longest interval, the uncertainty about S2 occurrence (introduced by catch trials) would produce a major effect at the longest interval, increasing MRTs.

\section{MATERIALAND METHODS}

\section{Subjects}

Other eight subjects (four male and four females) participated voluntarily in this experiment. All of them were righthanded according to the Edinburgh Inventory ${ }^{(21)}$ and had normal or corrected vision. They were undergraduate students at Federal Fluminense University, their ages ranged from 19 to 21 years, and they had never participated in previous experiments.

\section{Apparatus}

The apparatus was the same as in experiment 1 , except that this experiment ran on a Apple IIe microcomputer, the stimulus luminance was $7.5 \mathrm{~cd} / \mathrm{m}^{2}$ and the background luminance was $0.1 \mathrm{~cd} / \mathrm{m}^{2}$.

\section{Procedure}

Each trial began with the simultaneous presentation of a central point (fixation point - FP) and a square $\left(\mathrm{S} 1-0.5^{\circ} \times 0.5^{\circ}\right)$ located $4^{\circ}$ to the right of the central point. After $1000 \mathrm{~ms}, \mathrm{~S} 1$ went off and after a variable interval, the imperative stimulus (an identical square - S2) flashed for $100 \mathrm{~ms}$ around the central point. The interval between the offset of S1 and the onset of S2 varied randomly and with the same probability among 50, 250 and $1600 \mathrm{~ms}$ (Figure 5). In addition, the interval of $1600 \mathrm{~ms}$ varied randomly from 1300 to $1900 \mathrm{~ms}$. The subjects were instructed to fixate the FP and to use the offset of S1 as a cue for the onset of S2. They were also instructed to press a microswitch with the right index finger as soon as they detected S2. Subjects were notified that there were two different conditions on separate days: no-catch and catch conditions. In the no-catch condition subjects were informed that S2 would occur in $100 \%$ of the trials. In the catch condition, S2 would occur only $80 \%$ of the time. Therefore, in the latter, subjects were never sure about S2 occurrence. After each manual response the latency of that response (MRT) in milliseconds appeared on the screen for 1500 ms. Next trial began immediately after this presentation. All the subjects performed three sessions of 300 trials in separate days (approximately 30 minutes per session). Each session had four blocks of 75 trials and one or two minutes of resting between the blocks. The first session was considered training and its data were excluded from the statistical analysis. This session included separately one block of the catch condition and another of nocatch condition. In the second and third sessions, only one condition was used at a time. For $50 \%$ of the subjects the second session was performed on the catch condition and for the other $50 \%$, the no-catch condition was used instead. MRT

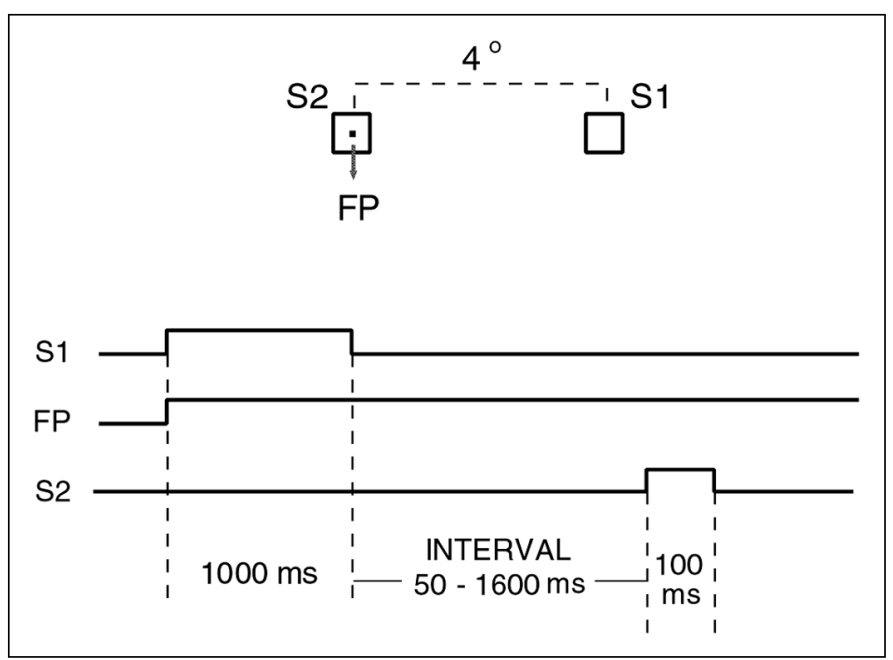

Figure 5 - Schematic representation of stimulus display; and temporal sequence of occurrence of fixation point (FP), the first - preparatory stimulus (S1) and the imperative stimulus (S2) for the second experiment 
shorter than $100 \mathrm{~ms}$ or longer than $700 \mathrm{~ms}$ were considered errors (anticipation and slow responses, respectively) and were discarded. Also, when subjects pressed the microswitch in a trial without $\mathrm{S} 2$ (catch trials), an error was committed. When one of these errors were detected, instead of the MRT, the messages "anticipation", "slow response" or "error" appeared on the screen for $1500 \mathrm{~ms}$. All errors-trials were repeated at the end of each session.

The medians of MRTs obtained in the second and third days were submitted to an analysis of variance (ANOVA) in which condition (no-catch and catch) and interval (50, 250 and $1600 \mathrm{~ms}$ ) were used as within-subjects factors. The data were also submitted to a post-hoc analysis using the NewmanKeuls method. The level of significance adopted was $p<0.05$.

\section{RESULTSAND DISCUSSION}

In this experiment, the error-trials corresponded to $3.66 \%$ (176 errors in 4800 trials), and almost all of them were anticipations $(93 \%)$. These anticipations tended to be equally distributed among subjects and between conditions ( $46 \%$ for nocatch and 54\% for catch condition). Subjects pressed the key in a trial without S2 ("catch trials") only 13 times.

The ANOVA showed a significant main effect of "interval" $(F(2.14)=7.418, p=0.006)$. There was also a significant interaction between "interval" and "condition" $(F(2.14)=$ $11.659, p=0.001)$. Figure 6 shows the mean MRTs for each interval and condition for the eight subjects. MRTs at interval 50 were 204 and $207 \mathrm{~ms}$ for no-catch and catch conditions, respectively; at interval 250, MRTs for these conditions were 192 and $193 \mathrm{~ms}$, respectively. The post-hoc analysis showed that MRTs at intervals 50 and 250 were statistically different. At these intervals, MRTs for both conditions did not present a significant difference. On the other hand, for interval 1600 ms, MRTs in the no-catch condition were shorter than in the catch condition (198 and $215 \mathrm{~ms}$, respectively). MRTs for intervals 250 and 1600 (192 and $198 \mathrm{~ms}$, respectively) did not differ in the no-catch condition. However, in the catch condition MRTs for interval $250(193 \mathrm{~ms})$ were shorter than those for interval $1600(215 \mathrm{~ms})$.

The results obtained in experiment 2 for the no-catch condition were similar to those observed in experiment 1 , showing that the facilitation at the longest interval was not due to the temporal prediction of target occurrence. Although in experiment 1 the longest interval had a fixed duration of $2000 \mathrm{~ms}$, in experiment 2 it varied randomly from 1300 to $1900 \mathrm{~ms}$ and, despite this, the presence of facilitation was evident. We observed, once again, facilitation at interval 250 for both conditions (no-catch and catch). Indeed, the most important result obtained in experiment 2 was the slowing down of MRTs at the longest interval in the catch condition. It means that when the occurrence of $\mathrm{S} 2$ was sure, expectancy was maximal and MRTs were minimal. However, when catch trials were introduced (20\% of the trials) MRTs increased, thus indicating that under this condition expectancy was smaller.

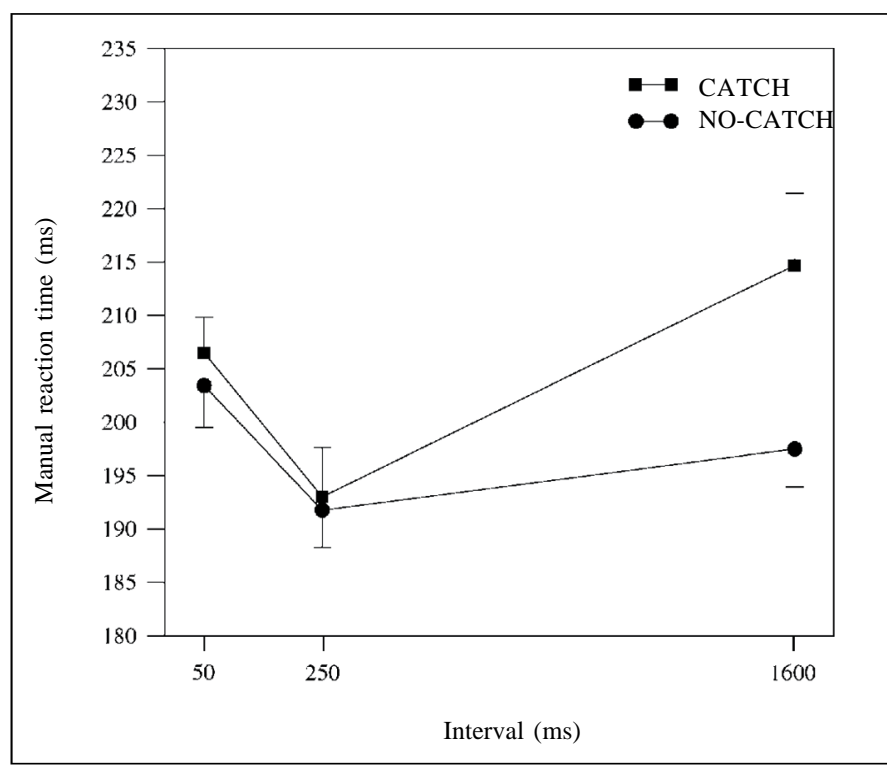

Figure 6 - Mean latency of manual reaction times (ordinate) as a function of interval (abscissa) and condition (CATCH x NO-CATCH) for the eight subjects. The error bars indicate \pm 1 standard error of the mean

GENER A L DISCUSSION

Initially, it is important to comment about the relevance of using a peripheral offset instead of a fixation offset in our experiments. First, it allows a comparison with the studies of Mayfrank et al. ${ }^{(15)}$ and Braun and Breitmeyer ${ }^{(16)}$, which also employed peripheral offsets. As the goal of this study was to compare our MRTs data with their SRTs data, it would be important to have similar procedures. The second reason is that by using peripheral offsets we could present S2 around the FP. This procedure is important to discourage the subjects to make an eye movement during the experiment. Since S2 would be detected more efficiently if their eyes were maintained on the FP the subjects would fare better in the tests if they avoid moving the eyes.

We commented, in the introduction, about the results obtained by Ross and $\operatorname{Ross}^{(2-3)}$ regarding the effects of FP changes on SRTs and MRTs. Both studies showed that differences between onset and offset were observed only for SRTs. However, as mentioned, data obtained by our group ${ }^{(4-5)}$ have shown that MRT can also be differently affected by the onset or the offset of a peripheral cue. There are some reasons to explain the discrepancy between our data and those obtained by Ross and Ross. First, we used simple motor responses (pressing of a key), while in the experiments of Ross and Ross subjects had to move a lever (to the left or to the right) upon the target's occurrence to generate the MRTs. Thus, while we used non-oriented responses and distal muscles, they used oriented motor responses and proximal muscles. Second, in the present work, onset and offset were intermixed and randomly distributed along the experiments. In the papers of 
Ross and Ross onset and offset were blocked. It means that in a block of trials only onset trials were adopted; offset trials were used in another block. In fact, in another experiment ${ }^{(22)}$ we found some evidences that the context in which offset and onset trials were presented (blocked vs non-blocked) does have an important role in determining MRT. Differences between onset and offset trials for MRTs were greater when nonblocked procedures were adopted.

In this study, the time course of the facilitation found for MRTs was similar to those obtained by Mayfrank et al. ${ }^{(15)}$, Braun and Breitmeyer ${ }^{(16)}$ and Saslow ${ }^{(6)}$ for SRTs. The best interval to produce facilitation on motor responses was 200$300 \mathrm{~ms}$. The similarity between our data and those obtained for saccades at short intervals suggest that both motor systems must share some common mechanisms. However, differently from the studies with SRTs, we also found a second facilitatory zone at longer intervals.

Based on their data, Kingstone and Klein ${ }^{(13)}$, Klein et al. ${ }^{(23)}$ and Reuter-Lorenz et al. ${ }^{(11)}$ proposed the so called two-component model to explain the gap effect. According to them, the reduction on motor responses observed in the gap paradigm would have two components: First, a warning component which follows any warning event (e.g., the offset of a visual stimuli) and is common for both saccadic and manual responses; second, a fixation offset component which is specific for saccades and is observed only when FP is turned off. This second component would be mediated by the fixation neurons $(\mathrm{FN})$ located in the rostral pole of superior colliculus ${ }^{(23)}$. According to this view, the offset of a foveal stimulus would decrease the inhibitory activity that FNs exert on collicular neurons involved with eye movements, decreasing saccades latency ${ }^{(24-28)}$. However, any involvement of collicular FNs with the observed reduction on MRTs is difficult to accept for two reasons: i) There is no evidence that the offset of a peripheral stimulus can also reduce the activity of FNs; and ii) the superior colliculus has little or nothing to do with movement of distal muscles, which were used in our procedures.

More recently, Forbes and Klein ${ }^{(29)}$, Taylor et al. ${ }^{(30)}$ and Trappenberg et al. ${ }^{(31)}$ introduced a third component to this hypothesis: an endogenous top-down interference due to some instructional or temporal prediction (previsibillity) of S2 occurrence. In fact, Findlay and Walker ${ }^{(32)}$ have also emphasized the involvement of the temporal component (the "when" component) in their model for saccade generation. We propose that the decreasing on MRTs observed in our experiments can also be attributed to this endogenous top-down effect.

In our view this endogenous top-down component is related to the preparatory mechanisms that follow the peripheral offset. In the case of SRTs experiments, preparation would be represented by the increased activity of build-up neurons of superior colliculus during the gap interval (for details about build-up activity in superior colliculus $\left.{ }^{(33-36)}\right)$. For MRTs, this motor preparation can also occur and maybe contribute to a decrease on motor latencies. In fact, using experimental procedures that involve an instructed delay period between a cue and the triggered movement, many papers have documented the effects of this motor preparation activity. This kind of activity has been shown to occur in many motor centers: the motor cortex ${ }^{(37-39)}$, the basal ganglia ${ }^{(40-42)}$ and also at spinal interneurons ${ }^{(43)}$. It seems obvious that for the development of this preparatory activity subjects must be able to predict the timing of target occurrence - temporal expectancy. We propose that the warning effect and the temporal expectancy effect are the major responsible for MRT decreasing observed in our experiments.

The involvement of expectancy in our results can be strongly suggested by the results of the second experiment. Only MRTs at the longest interval were affected by the introduction of catch trials. We believe that when catch trials were introduced (experiment 2), volunteers could not be sure about S2 occurrence, so their MRTs increased due to a less efficient preparatory activity.

The term expectancy has been used here as a synonym for motor preparation or preparatory set. The effects of expectancy/motor preparation in decreasing responses latencies and increasing performance are well known ${ }^{(44-49)}$. Some authors consider the Contingent Negative Variation (CNV) as an electroencephalographic (EEG) representation of these phenome$\mathrm{na}^{(45,47,50-51)}$. An important finding in this matter was obtained by Gomez et al. ${ }^{(52)}$. These authors found differences in cortical potentials between gap and non-gap (gap 0) paradigms. Using FP offset, they collected choice MRTs for gap-200 ms and gap-0 ms trials and showed that gap-200 induced some alterations in event-related potential which are compatible with expectancy of target occurrence by the subject. This finding corroborates the endogenous top-down influences proposed by Forbes and Klein ${ }^{(29)}$, Taylor et al. ${ }^{(30)}$ and Trappenberg et $\mathrm{al}^{(31)}$. It means that some cortical preparation really occur during the gap interval, and it has to do with the timing of target occurrence - temporal expectancy.

An interesting aspect of expectancy is that it could also be present at short intervals in a blocked array of intervals. When just one interval is used in a block of trials, it seems obvious that subjects will develop an expectancy to the timing of stimulus onset. We believe that in experiments that use fixed intervals, specially those without catch trials, part of the facilitation found in the gap paradigm may be due to this general effect called expectancy, since under these conditions subjects can be sure about the moment of the stimulus onset.

In the study of Braun and Breitmeyer ${ }^{(16)}$, using experimental procedures similar to those adopted for us, a population of express saccades was easily found. In the SRT distribution, they found a population of saccadic responses around the latency of 100-120 ms when the interval between the peripheral offset and the stimulus onset was 200-300 ms. They comment that for all (four) tested subjects, SRT distributions showed a similar pattern. In our study, MRT distribution showed shifts toward short latencies for intervals 200, 300 and 2000. However, data obtained in this and another study ${ }^{(53)}$ showed that distribution of MRTs tended to be more scattered than 
those observed for SRTs ${ }^{(17)}$. Despite this, for two subjects (\#2 and \#6), a peak of MRTs with short latencies (at about $180 \mathrm{~ms}$ ) emerged. For other subjects (\#1, \#4, \#7 and \#8) a peak of MRTs appeared at about 200-210 ms. Therefore, our data indicate that MRTs with short latencies (similar to the "Express Saccades" - "express MRT") can also be produced, at least for some subjects. As we cannot propose that fixation offset effect contributes to the reduction on MRTs observed here (see above), we are forced to conclude that warning and temporal expectancy are sufficient to induce leftward shifts in our distributions, forming a separate peak of short MRTs.

An intriguing finding of the present study is the fact that MRTs observed at short intervals were not affected by catch trials. These data apparently contrast with those obtained by Jüttner and Wolf ${ }^{(54)}$. In their study, fixed gap intervals were used $(200 \mathrm{~ms}$ ) and they found that SRTs increased as catch trials were introduced. However, I said "apparently" because the single interval used in their experiments was $200 \mathrm{~ms}$. Thus, we can interpret their results as another evidence that only the last tested interval is affected by catch trials, and the temporal context is a fundamental point to be considered in reaction times experiments. Therefore, their data corroborate our interpretation that temporal expectancy has a major influence at the longest tested interval.

Finally, if fixation offset effect really cannot be considered for manual responses and peripheral offsets, why are MRTs for short intervals so fast as those obtained for long intervals? Remember that if the reduction on MRTs were mainly due to temporal expectancy, so MRTs should be faster for longer than short intervals. There are two possibilities to explain it: i) we cannot completely discard that fixation or peripheral offsets are able to produce little or residual influences on MRTs at short intervals, just as fixation offsets reduce SRTs. If fixation offset really has notihng to do with limb movements, how can the results obtained by Bekkering et al. ${ }^{(55)}$ be explained? These authors found a significant gap effect for pointing and choice key-pressing movements. Moreover, other theories also admit that different motor systems (for example, manual responses) can be affected by the gap effect. This is the case of the "attentional theory" proposed by Fischer and coworkers (for details ${ }^{(7)}$ ). ii) Subjects could have adopted the strategy of generating two "expectancy waves" during the experiments, an early and a late one. The first "expectancy wave", addressed to the short intervals, for strategic reasons, would not be affected by catch trials. Top-down influences should induce an increasing in this early expectancy due to the high probability of target occurrence at short intervals.

In conclusion, our data support the hypothesis that the temporal component involved with the preparatory stages for motor responses can be shared by saccadic movements and key press responses, allowing the reduction in the latency of motor responses after the visual offset in the gap paradigm. In our view, however, the question for the existence of the gap effect for manual responses needs first to be addressed at the conceptual level. What does the gap effect really mean, for instance? Facilitation on MRTs after peripheral offset due to warning and preparation (endogenous top-down component) can be considered a "gap effect"? Or the gap effect should be considered a synonym of fixation offset effect? It will be thus necessary first to define "gap effect" in precise terms before concluding anything about its existence concerning other motor patterns beyond saccades.

\section{RESUMO}

Os tempos de reação manuais e sacádicos (TRMs e TRSs) são reduzidos quando um sinal de aviso precede o aparecimento do alvo. O decréscimo nos TRSs observados depois do desaparecimento do ponto de fixação tem sido chamado de efeito de intervalo. Teorias diferentes foram propostas para explicálo. De acordo com alguns autores, o desaparecimento também permite ao sistema sacádico gerar uma população separada de TRSs, as sacádicas expressas. No entanto, não há concordância sobre a influência do desaparecimento de um estímulo periférico no TRM. Em dois experimentos, testou-se os efeitos de um desaparecimento visual periférico empregado como um sinal preparatório para os TRMs a um alvo, após intervalos variáveis. Encontrou-se uma redução no TRM para intervalos curtos (200-300 ms) e longos (1300-2000 ms) após o desaparecimento periférico. A distribuição dos TRMs deslocou-se para latências curtas, formando por vezes populações separadas. Visto que os TRMs obtidos em intervalos longos foram afetados pela introdução de sessões capciosas, enquanto que os TRMs em intervalos curtos não o foram, propõe-se que dois mecanismos diferentes estão envolvidos no decréscimo dos TRMs: alerta e expectativa temporal. Nossos dados sustentam a hipótese de que o componente temporal envolvido com os estágios preparatórios das respostas motoras podem ser compartilhados pelos movimentos sacádicos e pelas respostas de apertar botões, permitindo a redução das latências motoras após o desaparecimento visual, dentro do paradigma do intervalo. Nossos dados corroboram o modelo de três componentes do efeito de intervalo. Em nosso ponto de vista, a questão da existência ou não do efeito de intervalo para respostas manuais é essencialmente conceitual.

Descritores: Tempo de reação; Preparação; Expectativa; Efeito de intervalo; Desaparecimento visual; Respostas expressas

\section{ACKNOWLEDGMENTS}

We would like to thank Dr. Carlos Eduardo Rocha-Miranda (Academia Brasileira de Ciências), Eliane Volchan (IBCCFUFRJ) and Dr. Ronald Ranvaud (ICB - USP) for their valuables comments on an earlier version of the manuscript. We are also grateful to Dr. Ricardo Gattass for suggesting the second experiment. Research supported by FINEP, CAPES, CNPq, PRONEX/MCT and PROPP-UFF. 


\section{REFERENCES}

1. James W. The Principles of Psychology. Vol. 1. Authorized edition. Dover Publications Inc., New York, 1890/1950.

2. Ross LE, Ross SM. Saccade latency and warning signals: stimulus onset, offset and change as warning events. Percept Psychophys 1980;27:251-7.

3. Ross SM, Ross LE. Saccade latency and warning signals: effects of auditory and visual stimulus onset and offset. Percept Psychophys 1981;29:429-37.

4. Gawryszewski LG, Thomaz TG, Machado-Pinheiro W, Sant'Anna AN. Onset and offset of a visual cue have different effects on manual reaction time to a visual target. Braz J Med Biol Res 1994;27:67-73.

5. Carreiro LRR, Gawryszewski LG, Magalhães FV, Tradardi V. Onset and offset inhibitions: effects of increase and decrease of cue luminance on manual reaction time to a visual target. Braz J Med Biol Res 1994;27:2645-51.

6. Saslow MG. Effects of components of displacement-step stimuli upon latency of saccadic eye movements. J Opt Soc Am 1967;57:1024-9.

7. Fischer B, Weber H. Express saccades and visual attention. Behav Brain Sci 1993; 16:553-610.

8. Fischer B, Boch R. Saccadic eye movements after extremely short reaction times in the monkey. Brain Res 1983;260:21-6.

9. Fischer B, Ramsperger E. Human express saccades: extremely short reaction times of goal directed eye movements. Exp Brain Res 1984;57:191-5.

10. Reuter-Lorenz PA, Hughes HC, Fendrich R. The reduction of saccade latency by prior offset of the fixation point: An analysis of the gap effect. Percept Psychophys 1991;49:167-75.

11. Reuter-Lorenz PA, Oonk HM, Barnes LL, Hughes HC. Effects of warning signals and fixation point offsets on the latency of pro- versus antisaccades: implications for an interpretation of the gap effect. Exp Brain Res 1995;103: 287-93.

12. Fendrich R, Hughes HC, Reuter-Lorenz PA. Fixation-point offsets reduce the latency of saccades to acoustic targets. Percept Psychophys 1991;50:383-7.

13. Kingstone A, Klein RM. What are human express saccades? Percept Psychophys 1993a;54:260-73.

14. Kingstone A, Klein RM. Visual offsets facilitate saccadic latency: does predisengagement of visuospatial attention mediates the gap effect? J Exp Psychol Hum Percept Perform 1993b;19:1251-65.

15. Mayfrank L, Mobashery M, Kimming H, Fischer B. The role of fixation and visual attention in the occurrence of express saccades in man. Eur Arch Psychiatry Neurol Sci 1986;235:269-75.

16. Braun D, Breitmeyer BG. Relationship between directed visual attention and saccadic reaction times. Exp Brain Res 1988;73:546-52.

17. Rogal L, Reible G, Fischer B. Reaction times of the eye and the hand of the monkey in a visual reach task. Neurosci Lett 1985;58:127-32.

18. Fischer B, Rogal L. Eye-hand-coordination in man: a reaction time study. Biol Cybern 1986;55:253-61.

19. Fischer B. Visually guided eye and hand movements in man. Brain Behav Evol 1989;33:109-12.

20. Iwasaki S. Facilitation of reaction times with gap paradigm: comparison of manual and saccadic responses. Ergonomics 1990;33:833-50.

21. Oldfield RC. The assessment and analysis of handiness: The Edinburgh inventory. Neuropsychologia 1971;9:97-113.

22. Machado-Pinheiro W. Influência de fenômenos alertantes e atencionais na gênese das respostas manuais e sacádicas. Doctoral's Thesis, Instituto de Ciências Biomédicas, Universidade de São Paulo, São Paulo; 1999.

23. Klein R, Taylor TL, Kingstone A. Against a role for attentional disengagement in the gap effect: A friendly amendment to Tam and Stelmach (1993). Percept Psychophys 1995;57(4):573-7.

24. Dorris MC, Munoz DP. A neural correlate for the gap effect on saccadic reaction times in monkey. Journal of Neurophysiol 1995;73(6):2558-62.

25. Dorris MC, Paré M, Munoz DP. Neuronal activity in monkey superior colliculus related to the initiation of saccadic eye movements. J Neurosci 1997; 17(21):8566-79.

26. Munoz DP, Guitton D. Control of orienting gaze shifts by tectoreticulospinal system in the head-free cat. II. Sustained discharge during motor preparation and fixation. J Neurophysiol 1991;66(5):1624-41.

27. Munoz DP, Wurtz RH. Role of the rostral superior colliculus in active visual fixation and execution of express saccades. J Neurophysiol 1992;67(4):1000-2.
28. Munoz DP, Wurtz RH. Fixation cells in monkey superior colliculus. I. Characteristics of cell discharge. J Neurophysiol 1993a;70(2):559-75.

29. Forbes K, Klein RM. The magnitude of the fixation offset effect with endogenously and exogenously controlled saccades. J Cognit Neurosci 1996;8(4): 344-52.

30. Taylor TL, Kingstone A, Klein RM. The disappearance of foveal and nonfoveal stimuli: decomposing the gap effect. Can J Exp Psychol 1998;52(4):192-9.

31. Trappenberg TP, Dorris, MC, Munoz, DP, Klein, RM. A model for saccade initiation based on the competitive integration of exogenous and endogenous signals in the superior colliculus. J Cognit Neurosci 2001;13(2):256-71.

32. Findlay JM, Walker R. A model of saccade generation based on parallel processing and competitive inhibition. Behav Brain Sci 1999;22:661-721.

33. Munoz DP, Wurtz RH. Saccade Related activity in the monkey superior colliculus. I. Characteristics of burst and buildup cells. J Neurophysiol 1995a; 73(6):2313-33

34. Munoz DP, Wurtz RH. Saccade Related activity in the monkey superior colliculus. II. Spread of activity during saccades. J Neurophysiol 1995b;73(6): 2334-48.

35. Paré M, Munoz DP. Saccadic reaction time in the monkey: Advanced preparation of oculomotor programs is primarily responsible for express saccade occurrence. J Neurophysiol 1996;76(6):3666-81.

36. Basso MA. Cognitive set and oculomotor control. Neuron 1998;21:665-8.

37. Schmidt EM, Jost RG, Davis KK. Cortical cell discharge patterns in anticipation of a trained movement. Brain Res 1974;75:309-11.

38. Tanji J, Evarts EV. Anticipatory activity of motor cortex neurons in relation to direction of an intended movement. J Neurophysiol 1976;39(5):1062-8.

39. Kubota K, Hamada I. Preparatory activity of monkey pyramidal tract neurons related to quick movement onset during visual tracking performance. Brain Res 1979;168:435-9.

40. Alexander GE. Selective neuronal discharge in monkey putamen reflects intended direction of planned limb movements. Exp Brain Res 1987;67:623-34.

41. Alexander GE, Crutcher MD. Preparation for movement: neural representations of intended directions in three motor areas of the monkey. J Neurophysiol 1990;64:133-50.

42. Apicella P, Scarnati E, Ljungberg T, Schultz W. Neuronal activity in the monkey striatum related to the expectation of predictable enviromental events. J Neurophysiol 1992;68(3):945-60.

43. Prut Y, Fetz EE. Primate spinal interneurons show pre-movement instructed delay activity. Nature 1999;401:590-4.

44. Bertelson P. The time course of preparation. Q J Exp Psychol 1967;19:272-9.

45. Birbaumer N, Elbert T, Canavan AGM, Rockstroh B. Slow potentials of the cerebral cortex and behavior. Physiol Rev 1990;70:1-41.

46. Boelhouwer AJW, Scheirs JGM, Blumenthal TD. The effect of response preparation upon the early component of the human blink reflex. J Psychophysiol 1996;9:61-9.

47. Gaillard AW, Näätänen R. Slow potential changes and choice reaction time as function of interstimulus interval. Acta Psychol 1973;37:173-86.

48. Posner MI, Cohen Y. Attention and the control of movements. In: Stelmach GE, Requin J, editors, Tutorials of Motor Behavior. Amsterdam: North Holland Publishing Co.; 1980, p.243-58.

49. Posner MI, Klein RM, Summers J, Buggie, S. On the selection of signals. Mem Cogn 1973;1:2-12.

50. Posner MI (1975). Psychobiology of attention. In: Gazzaniga M, Blakemore C, editors, Handbook of Psychology. New York: Academic Press. 1975, p.441-80.

51. Posner MI. Chronometric Exploration of Mind. Hillsdale: Erlbaum Associates, 1978.

52. Gómez C, Atienza M, López-Mendoza D, Gómez GJ, Vásquez M. Cortical potentials during gap and non-gap paradigms using manual responses in humans. Neurosci Lett 1995;186:107-10.

53. Machado-Pinheiro W, Gawryszewski LG, Ribeiro-do-Valle LE. Gap effect and reaction time distribution: simple vs. choice manual responses. Braz J Med Biol Res 1998;31:1313-8.

54. Jüttner M, Wolf W. Human express saccades: catch trials influence the probability of their occurrence. In: Schimdt R, Zambarbieri, editors, Oculomotor Control and Cognitive Processes. North Holland: Elsevier Science Pub; 1991, p.163-75.

55. Bekkering H, Pratt J, Abrams RA. The gap effect for eye and hand movement. Percept Psychophys 1996;58:628-35. 